OPEN ACCESS

Edited by:

Hector Wing Hong Tsang,

Hong Kong Polytechnic University,

Hong Kong SAR, China

Reviewed by:

Miyuru Chandradasa,

University of Kelaniya, Sri Lanka

Florian Riese,

University of Zurich, Switzerland

*Correspondence:

Li Kuang

kuangli0308@163.com

Specialty section:

This article was submitted to Social Psychiatry and Psychiatric

Rehabilitation,

a section of the journal

Frontiers in Psychiatry

Received: 22 November 2021

Accepted: 17 January 2022

Published: 14 February 2022

Citation:

Li X, Ai M, Chen X, Gan Y, He J, Tian $Y$, Zhai J, Yang $H$ and Kuang $L$ (2022) Attitudes Toward Psychiatry Among Medical Students With a

Psychiatric Major at Chongqing Medical University.

Front. Psychiatry 13:820060

doi: 10.3389/fpsyt.2022.820060

\section{Attitudes Toward Psychiatry Among Medical Students With a Psychiatric Major at Chongqing Medical University}

\author{
Xiao $\mathrm{Li}^{1}$, Ming $\mathrm{Ai}^{1}$, Xiaolu Chen ${ }^{2}$, Yao Gan ${ }^{1}$, Jinglan $\mathrm{He}^{1}$, Yu Tian ${ }^{3}$, Jian Zhai ${ }^{1}$, \\ Haoling Yang ${ }^{4}$ and Li Kuang ${ }^{1 *}$ \\ ${ }^{1}$ Department of Psychiatry, The First Affiliated Hospital of Chongqing Medical University, Chongqing, China, ${ }^{2}$ The First \\ Branch, The First Affiliated Hospital of Chongqing Medical University, Chongqing, China, ${ }^{3}$ Department of the First Clinical \\ Medicine, Chongqing Medical University, Chongqing, China, ${ }^{4}$ Department of Oncology, The First Affiliated Hospital of \\ Chongqing Medical University, Chongqing, China
}

Objectives: To understand the attitudes of medical students with a psychiatry major toward psychiatry at Chongqing medical university in China and to find out factors influencing students' career choice.

Methods: The present study used an online web survey tool to assess the attitudes toward psychiatry amongst 422 students majoring in psychiatry at Chongqing medical university in China using sociodemographic and Attitudes Toward Psychiatry-30 items (ATP-30) scales. Descriptive statistics and logistic regression analysis were used to examine associated factors.

Results: Three hundred and sixty-nine students (87\%) answered the questionnaire. Nearly $54.5 \%$ of participants had overall positive attitudes to psychiatry and $80.8 \%$ thought psychiatrist could be a career choice. Of the students, $5.1 \%$ showed that they did not want to be a psychiatrist while the remaining $14.1 \%$ were undecided. The first and fifth year students showed less desire to be a psychiatrist (74.3 and $69.8 \%$, respectively); the highest percentage recorded is of the third year (90.6\%). Female participants, in contact with patients suffering from mental illness, were willing to study psychiatry as a master degree and see good prospects were positive factors in choosing psychiatry as a career.

Conclusions: Students generally have good expectations toward psychiatry, but different opinions are also held and the field is still faced with various challenges in order to provide more psychiatrists.

Keywords: psychiatry, attitude, career choice, medical students, psychiatry major

\section{INTRODUCTION}

Mental health is an essential component of health. Mental disorders can affect not only individual quality of life but also national productivity (1). Although the burden of mental illnesses has been increasing worldwide, such increases may be more dramatic in China (2), which can partly be understood as a consequence following rapid social changes in recent decades. Unfortunately, mental health services in China are insufficient to respond to the extensive 
mental disorders prevalent in the country. In 2004, the total number of licensed psychiatrists in China was 16,103 (1.24 psychiatrists per 100,000 people), with 557 psychiatric hospitals with 129,314 psychiatric beds (9.95 per 100,000) nationwide (3). In 2015 , the number increased to 27,733 (2.01 psychiatrists per 100,000 people), and 2,936 mental health services with approximately 433,000 psychiatric beds $(31.5$ per 100,000$)$ (4), but based on the World Health Organization (WHO)'s Mental Health Atlas (5), the proportion of psychiatrists in 2014 was about 20.1 per 100,000 in Japan.

There is a serious shortage of psychiatrists in China, therefore, the training of psychiatrists is of great importance, but many previous studies have consistently shown that psychiatry was not the top specialty choice for vocation among medical students in different countries (6-10). Although many factors, such as gender (11) and grades (12), will influence a medical student's career choice for psychiatry, attitudes about psychiatry play a key role $(9,10,13)$. In previous studies, positive views on psychiatry, such as it being an intellectual challenge, and efficacy of psychiatry $(14,15)$ were seen, but there are some negative opinions associated with it, for instance, the lack of scientific foundation (16), low social status, relatively low income (14, 15 ), and poor personal image of psychiatrists in society (17). Generally speaking, whether or not to work as a psychiatrist is determined by complex factors and still worthy to study.

The Chongqing Medical University in Chongqing, China, was established in 1956, and provides psychiatry courses ranging from bachelor's to Master's Degree/Ph.D. In order to train more psychiatrists, the school established clinical medicine (mental hygiene specialty) in 2006. Ai investigated the employment situations of 390 students of clinical medicine (mental hygiene specialty) from grade 2006 to 2011 and found only $16.36 \%$ of them selected to be a psychiatrist (18). In 2016, the school introduced psychiatry as a major, which trained approximately 80 medical students majoring in psychiatry every year. Compared with undergraduate psychiatry education in the standard Chinese clinical medicine curriculum (CMC), medical students with a psychiatric major will take a psychiatry major curriculum (PMC), which provides more comprehensive exposure to psychiatry than CMC, with more preclinical experiences and psychiatry clerkship course hours. Nonetheless this does not mean all the students voluntarily select the PMC; there were 422 students majoring in psychiatry since 2016, but about $57.7 \%$ of them were placed into it from other majors upon admission to the university.

Our study explored the attitudes of psychiatry-majoring students in Chongqing medical school toward psychiatry. We conducted this research because: (1) Most studies are aimed at students of all majors. There are few studies on the attitudes of medical students with a psychiatry major, so it would be worthy to explore whether they would be more willing to be a psychiatrist; (2) we wished to explore what affects the choice of students when they face their career choice; and (3) Most of the studies are concentrated in the United States, the United Kingdom, Israel, and other countries. In western China, this type of study has not yet been found, so we hope to understand the attitude of students here.

\section{METHODS}

\section{Sample}

An online sociodemographic questionnaire and Attitudes Toward Psychiatry-30 items (ATP-30) were sent to all students majoring in psychiatry $(n=422)$ at Chongqing Medical University, China. 369 (87\%) students submitted the online questionnaire and gave full information.

\section{Design}

The study consisted of a two-part questionnaire consisting of a self- administered scale and ATP-30, Chinese version. The ATP-30 was designed by Burra et al. (19). It was mainly used to measure the attitudes of medical students toward psychiatry, although now the scale has been widely used (20-22). ATP-30 focuses on attitudes and views of psychiatry with 30 questions. There are 5 choices for each question: strongly agree, agree, neutral, disagree, and strongly disagree. It contains 30 Likertscale items, 5 means strongly agree and 1 means strongly disagree. These questions focus on many aspects of psychiatry, for example, the views on mental illness, psychiatrists, treatment, and on that of choosing to become a psychiatrist in the future. The total score ranged between 30 and 150 points. A score of 90 means "the logical neutral point of the scale," scores more than 90 mean a more positive attitude (20). Students with a psychiatry major were invited to participate in the study from March 2021 to May 2021; there is no identity disclosure or financial compensation. Ethical approval was granted by the Chongqing Medical University, and informed consent was obtained from all participants.

\section{Statistical Analyses}

We used "Tencent questionnaire" (an online web survey tool) to collect the data, and the statistical analysis was performed by SPSS version 25.0. We used descriptive statistics for counts $(n)$, proportions (\%), or means with standard deviations (SD). Multiple logistic regression analysis was used to find significant factors with the ATP-30 item 4 (I would like to be a psychiatrist), these factors include gender, income, and contact with psychiatric patients. Answers of item 4 were divided into 3 categories: "strongly agree," "agree" were divided into the "agree" category, while "strongly disagree," and "disagree" were divided into the "disagree" category, "neutral" remained as a category on its own. $P<0.05$ was considered significant in this study.

\section{RESULTS}

Three hundred and sixty-nine students $(87.4 \%, 369 / 422)$ finished both questionnaires, of which 106 were males (28.7\%). Table 1 summarizes the demographic characteristics of the participants.

Out of the 369 students who answered all the ATP-30 items, about $54.5 \%$ responded for positive attitudes to psychiatry, $39 \%$ of them showed generally negative attitudes, and $6.5 \%$ were neutral.

More females reported favorable attitudes to psychiatry compared to males (56.7\% to $49 \%$ ). More than $40 \%$ (48.7 to 43 to $41.3 \%$ ) of students in the 1 st, 2 nd, and 5 th year, respectively, 
TABLE 1 | Demographic Characteristics of participants $(n=369)$.

\begin{tabular}{|c|c|c|}
\hline Characteristic & $N$ & $\%$ \\
\hline \multicolumn{3}{|l|}{ Gender } \\
\hline Male & 106 & 28.7 \\
\hline Female & 263 & 71.3 \\
\hline \multicolumn{3}{|l|}{ Have siblings } \\
\hline Yes & 177 & 48 \\
\hline No & 192 & 52 \\
\hline \multicolumn{3}{|c|}{ Monthly total income of all the family members (RMB) } \\
\hline$<3,000$ & 84 & 22.8 \\
\hline $3,000-8,000$ & 142 & 38.5 \\
\hline$>8,000$ & 143 & 38.7 \\
\hline \multicolumn{3}{|c|}{ Contact with psychiatric patients } \\
\hline Yes & 184 & 49.9 \\
\hline No & 185 & 50.1 \\
\hline \multicolumn{3}{|c|}{ Willing to become a psychiatrist in the future } \\
\hline Yes & 298 & 80.8 \\
\hline Neutral & 52 & 14.1 \\
\hline No & 19 & 5.1 \\
\hline \multicolumn{3}{|c|}{ Willing to study for psychiatric master degree } \\
\hline Yes & 298 & 80.8 \\
\hline Neutral & 50 & 13.6 \\
\hline No & 21 & 5.6 \\
\hline \multicolumn{3}{|c|}{ Psychiatry as the first chosen major } \\
\hline Yes & 156 & 42.3 \\
\hline No & 213 & 57.7 \\
\hline \multicolumn{3}{|c|}{ The prospects of the psychiatry major } \\
\hline Good & 258 & 69.9 \\
\hline Neutral & 92 & 24.9 \\
\hline Bad & 19 & 5.2 \\
\hline
\end{tabular}

reported negative attitudes. In contrast, to other grades, a higher percentage (more than 55\%) of participants in their last 3 years of study showed positive attitudes to psychiatry (Table 2).

The answers to item 4 of the ATP-30 ("I would like to be a psychiatrist") were considered particularly significant because they provided the attitude of career choice in the future. The details of this item are presented in Table 3. In total, about $80.8 \%$ of the students expressed that they would choose to be a psychiatrist, but for the first year and the fifth year, the rate is relatively lower $(74.3 \%$ and $69.8 \%)$; the highest one is the 3 rd year (90.6\%) (Table 3).

Regression analysis showed that gender $(p=0.041)$, contact with psychiatric patients $(p=0.003)$, those willing to study for a Master's Degree of psychiatry $(p<0.001)$, and good prospects in psychiatry $(p<0.001)$ were significantly associated with the wish to be a psychiatrist (Table 4).

From the results of ATP-30, in general, the students believe that psychiatry should be paid enough attention and respect. Psychiatry is interesting and psychiatric treatment is effective (item: 11, 12, 18). Most students disagree that there is a lack of science in psychiatry, or psychiatric treatment is cruel and ineffective, or that psychiatric treatment is useless (item: 2, 7,
TABLE 2 | Global ATP-30 scores by gender and grade $(n=369)$.

\begin{tabular}{lcccc}
\hline Variable & $\boldsymbol{n}$ & $\begin{array}{c}\text { Unfavorable } \\
\text { ATP-30 }<\mathbf{9 0} \text { (\%) }\end{array}$ & $\begin{array}{c}\text { Neutral } \\
\text { ATP-30 }=\mathbf{9 0} \text { (\%) }\end{array}$ & $\begin{array}{c}\text { Favorable } \\
\text { ATP-30 }>\mathbf{9 0} \text { (\%) }\end{array}$ \\
\hline Gender & & & & \\
Male & 106 & 45.3 & 5.7 & 49 \\
Female & 263 & 36.5 & 6.8 & 56.7 \\
Total & 369 & 39 & 6.5 & 54.5 \\
Grade & & & & 55.5 \\
5th & 63 & 41.3 & 3.2 & 59 \\
4th & 78 & 30.7 & 10.3 & 62.5 \\
3rd & 64 & 29.7 & 7.8 & 52.3 \\
2nd & 86 & 43 & 4.7 & 44.9 \\
1st & 78 & 48.7 & 6.4 & \\
& & & &
\end{tabular}

TABLE 3 | "I would like to be a psychiatrist" in different grade (item 4 on ATP-30).

\begin{tabular}{|c|c|c|c|c|c|}
\hline \multirow[b]{2}{*}{$\begin{array}{l}\text { Years of } \\
\text { study }\end{array}$} & \multicolumn{4}{|c|}{ Rating $n(\%)$} & \multirow[b]{2}{*}{$\begin{array}{c}\text { Strongly } \\
\text { agree }\end{array}$} \\
\hline & $\begin{array}{c}\text { Strongly } \\
\text { agree }\end{array}$ & Agree & Neutral & Disagree & \\
\hline 1 & 26 (33.3) & $32(41)$ & 17 (21.8) & $2(2.6)$ & $1(1.3)$ \\
\hline 2 & $23(26.7)$ & $53(61.6)$ & $8(9.3)$ & $1(1.2)$ & $1(1.2)$ \\
\hline 3 & $16(25)$ & $42(65.6)$ & $4(6.3)$ & 0 & $2(3.1)$ \\
\hline 4 & $24(30.8)$ & $38(48.7)$ & $11(14.1)$ & $4(5.1)$ & $1(1.3)$ \\
\hline 5 & 12 (19) & $32(50.8)$ & 12 (19) & $6(9.5)$ & $1(1.6)$ \\
\hline
\end{tabular}

19) [Figure 1: Mean and SD of the Attitudes Toward Psychiatry (ATP-30) items].

\section{DISCUSSION}

\section{Total Opinions From Students}

Our results showed that $54.5 \%$ of students had positive attitudes to psychiatry and $80.8 \%$ expressed they would choose to be a psychiatrist. One study from 20 countries reported about $23.5 \%$ of students thought being a psychiatrist could be a "definitely or quite likely" career choice (24). Another study showed a dissonance between positive attitude $(74.9 \%)$ and career choice (14.3\%) to psychiatry (12). In our study, the proportion of wish to be a psychiatrist is rather high; this may be attributed to the following reasons: (1) the study focuses on the students of psychiatry major, who have a higher likelihood to have voluntarily selected to study psychiatry; (2) the 2020 Science and Technology Evaluation Metrics (STEM) of China's hospitals, which were based on the integration of production, teaching, and research, revealed the development of science and technology in medical colleges and universities in a comprehensive approach. It showed psychiatry in the first affiliated hospital of Chongqing Medical University ranked 6th among all the hospitals (25), furthermore, it is the only university providing psychiatric degree programs in Chongqing. The students may have more confidence in the major and have more optimistic expectations about being a psychiatrist in the future; and (3) we made a 5-year full tutorial system for students when they entered the program. The tutors would lead students to participate in clinical and scientific 
TABLE 4 | Multiple logistic regression model for "ATP item 4."

\begin{tabular}{|c|c|c|c|c|c|}
\hline \multirow{2}{*}{$\begin{array}{l}\text { Variables } \\
\text { "I am willing to be a psychiatrist" }\end{array}$} & \multirow[b]{2}{*}{ Disagree } & \multirow{2}{*}{$\begin{array}{c}\text { OR } \\
0.143\end{array}$} & \multicolumn{2}{|c|}{$95 \% \mathrm{Cl}$} & \multirow{2}{*}{$\frac{\boldsymbol{P}}{0.008^{*}}$} \\
\hline & & & -.398 & -0.498 & \\
\hline & Neutral & 0.826 & -1.598 & 1.215 & 0.79 \\
\hline & Agree & Ref & & & Ref \\
\hline \multirow[t]{2}{*}{ Gender } & Male & 0.502 & -1.352 & -0.028 & $0.041^{*}$ \\
\hline & Female & Ref & & & Ref \\
\hline \multirow[t]{2}{*}{ Have siblings } & No & 1.298 & -0.417 & 0.938 & 0.451 \\
\hline & Yes & Ref & & & Ref \\
\hline \multirow[t]{3}{*}{ Monthly total income of all the family members (RMB) } & $<3,000$ & 0.997 & -0.833 & 0.828 & 0.995 \\
\hline & $3,000-8,000$ & 1.057 & -0.674 & 0.784 & 0.883 \\
\hline & $>8,000$ & Ref & & & Ref \\
\hline \multirow[t]{2}{*}{ Contact with psychiatric patients } & No & 0.978 & -0.637 & 0.594 & $0.003^{\star}$ \\
\hline & Yes & Ref & & & Ref \\
\hline \multirow[t]{3}{*}{ Willing to study for master degree of psychiatry } & No & 0.169 & -2.867 & -0.689 & $0.001^{*}$ \\
\hline & Neutral & 1.42 & -0.492 & 1.194 & 0.414 \\
\hline & Yes & Ref & & & Ref \\
\hline \multirow[t]{2}{*}{ Psychiatry as the first chosen major } & No & 1.195 & -0.503 & 0.86 & 0.608 \\
\hline & Yes & Ref & & & Ref \\
\hline \multirow[t]{3}{*}{ The prospects of the psychiatric major } & Good & 10.095 & 1.093 & 3.532 & $0.001^{*}$ \\
\hline & Neutral & 0.773 & -1.32 & 0.804 & 0.634 \\
\hline & Bad & Ref & & & Ref \\
\hline
\end{tabular}

Ref, reference group. ${ }^{*} P<0.05$.

research work, and established a relatively strong interest in the early stage.

We noticed that the attitudes toward psychiatry in different grades are different; for the first-year group, students showed higher unfavorable attitudes, in fact, previous studies $(16,17)$ showed that the lower grades had a more positive attitude toward psychiatry than the higher grades, which was different from our study. Possible reasons may be the freshmen do not know much about psychiatry, and they may believe stereotypes regarding mental illness and the patients. Another possible reason may also be most of them do not voluntarily select the psychiatry major but are placed into psychiatry upon admission to the university.

A similar phenomenon was also found in the fifth-year group. This may be due to the fact that more factors will affect students' career choice as they approach graduation, such as low social status (14), relatively low income of psychiatry (15), the poor personal image of psychiatrists in society (17), and no opportunity to perform clinical skills (16). Similar results have been reported in Israel (23) and Pakistan (26).

Students showed the highest favorability to psychiatry during 3rd and 4th year; this may be because they begin their psychiatry exposure in these 2 years. The psychiatry major students in the Chongqing Medical University were introduced to clinical exposure to psychiatry (such as child and adolescent psychiatry, geriatric psychiatry, etc.) during the 3rd and 4th years. Some previous studies showed more positive attitudes after exposure to psychiatry $(11,27-29)$, while others showed opposite results $(30,31)$ or no effect $(32)$. The difference may indicate that the effect of clinical exposure is influenced by complex factors.

\section{The Factors Impact the Career Choice}

In our study, we found females had more favorable attitudes toward psychiatry and more willingness to be a psychiatrist. This result was similar to most previous studies $(33,34)$ but not to all $(35,36)$. The findings also showed more females would like to be a psychiatrist (30); the reason might be the so-called psycho-social disciplines by female students and doctors, which have been demonstrated in previous studies $(37,38)$. Another finding in our study is contact with mental illness patients might be a positive contributing factor to being a psychiatrist. This result is similar to many previous studies $(39,40)$, but opposite results are also found in other studies (16). One study found (24) that, compared with inpatients, contact with outpatients makes students more willing to choose to become a psychiatrist in the future, and the study also showed that contact with patients with mental illness during the recovery period will make students more willing to choose to become psychiatrists than contact with patients with acute mental illness. In our study, most of the psychiatric patients contacted by students are relatives or friends who have more positive emotion and symptoms which are not so severe. This may be the reason for the differences in this study. Willingness to study for a master's degree in psychiatry and have good prospects of psychiatry are also positive factors to be a psychiatrist in the future. There are also related studies in the past (15), suggesting that better expectations for psychiatry indicate a greater chance of choosing to become a psychiatrist in the future.

\section{Individual Questions From the ATP-30}

The results shown in Figure 1 provide some information for different factors that lead to both negative and positive attitudes. The attitudes of medical students are generally quite positive. 


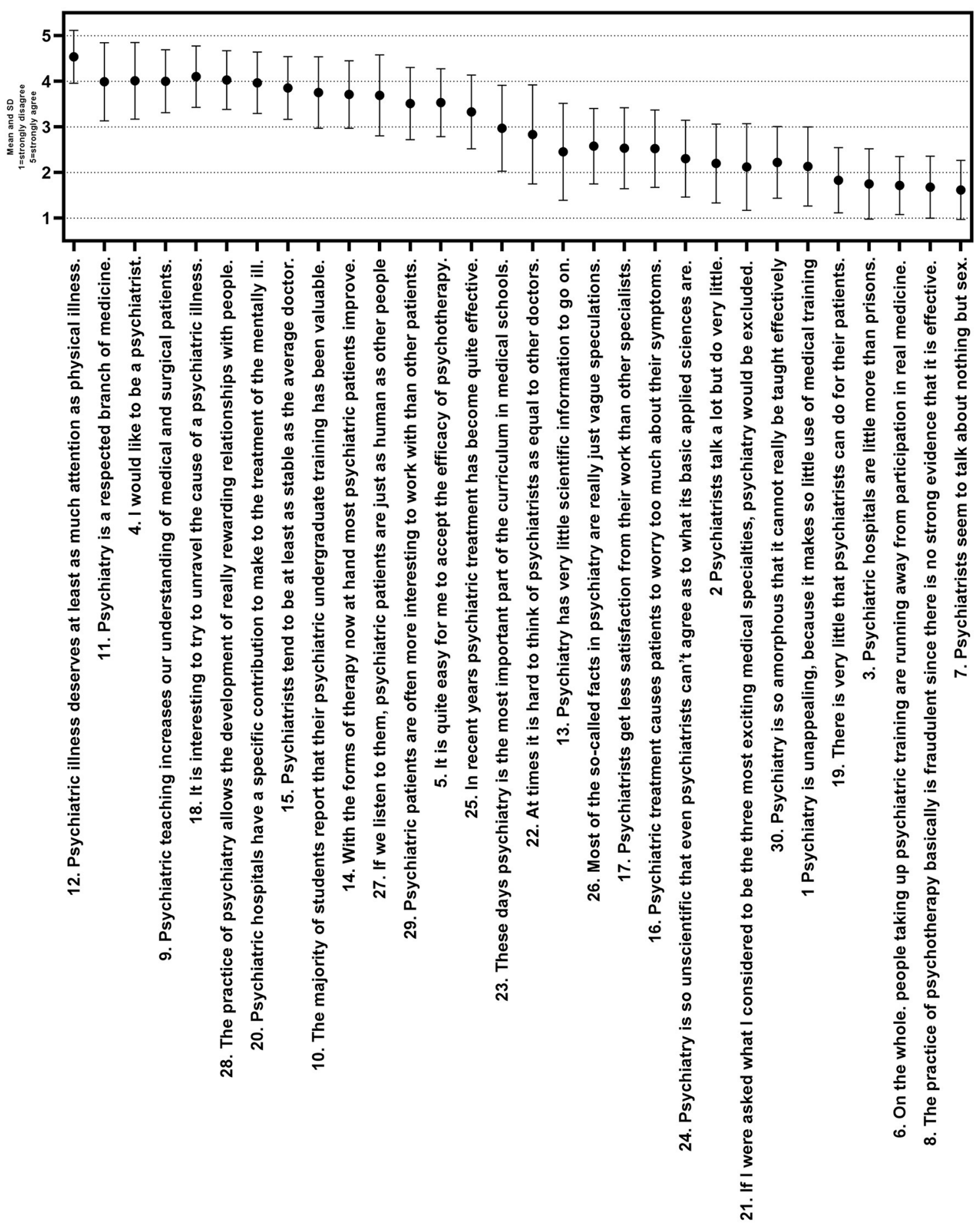

FIGURE 1 | ATP-30 items according to the ATP-30.

Among notable positive attitudes, students mostly see psychiatry as a valid branch of medicine, the treatment of psychiatry is effective, and patients really get cured by modern treatments. A majority of the students holding negative opinions are mainly due to the low professional achievement of psychiatrist, where they think psychiatric hospitals are like prisons, or psychiatrists always talk about sex, which is still a topic of taboo in China.

For instance, $19.8 \%$ of students agreed that psychiatry has very little scientific information to go on, pointing out a possible poor scientific view for psychiatry. This view has been shown many times in different studies $(16,23)$; this is also one of the most 
controversial questions. To the question, $16 \%$ strongly disagreed, $46.1 \%$ disagreed, $18.2 \%$ were neutral, $15.7 \%$ agreed, and $4.1 \%$ strongly agreed. One possible reason might be the psychiatric diagnosis was not based on physical findings or laboratory tests but mainly the symptoms.

Another controversial statement in the questionnaire was probably the one that "Psychiatrists get less satisfaction from their work than other specialists." To the question, $10 \%$ strongly disagreed, $48.2 \%$ disagreed, $31.4 \%$ were neutral, $15.2 \%$ agreed, and $0.5 \%$ strongly agreed. This question may involve complex factors, such as views about low status, the patient's treatment effect, income, and others (14-16).

Questions like "Psychiatrists seem to talk about nothing but sex (item 7)" and "Psychiatric hospitals are little more than prisons (item 3)," shows significant stigmatization of patients, psychiatrists, and psychiatry. This stigmatization has also been found in many studies, and it may cause students to give up working in psychiatric-related fields after graduation (11, 12, 38). However, in our study, most students disagreed with these views. Possible reasons may be when students enter the school in their freshman year, the teachers will schedule hold lectures and comprehensively introduce all aspects of psychiatry, which may involve the development of psychiatric treatment, psychiatry used in daily life, and the benefit of psychiatry for individuals. This could cultivate students' enthusiasm for psychiatry and eliminate misunderstandings about psychiatry. At the same time, every semester, there will be 3-4 weeks for students to visit wards and outpatient clinics and the students will have preclinical experience (41), but even so, mental illness patients and psychiatric hospitals are misunderstood by the general public, so it still requires more correct guidance from society and the country.

This study also has some limitations: (1) it focuses on the attitudes of psychiatry major students, but not all medical students in Chongqing Medical University. In the following study, we will include more participants from different specialties; and (2) this study contains limited factors, for example, research on teacher-student relationship, teaching methods, and other related factors that can be included in the following study.

\section{CONCLUSION}

This study found that the majority of students endorsed favorable attitudes toward psychiatry, while gender and personal patient

\section{REFERENCES}

1. Saxena S, Thornicroft G, Knapp M, Whiteford H. Resources for mental health: scarcity, inequity, and inefficiency. Lancet. (2007) 370:878-89. doi: 10.1016/S0140-6736(07)61239-2

2. Guo WJ, Tsang A, Li T, Lee S. Psychiatric epidemiological surveys in China 1960-2010: how real is the increase of mental disorders? Curr Opin Psychiatry. (2011) 24:324-30. doi: 10.1097/YCO.0b013e3283477b0e

3. Liu J, Ma H, He YL, Xie B, Xu YF, Tang HY, et al. Mental health system in China: history, recent service reform and future challenges. World Psychiatry. (2011) 10:210-16. doi: 10.1002/j.2051-5545.2011.tb00059.x contact clearly influence students' attitudes. Willingness to take a master's degree study of psychiatry, as well as good prospects of psychiatry, appear to be positive factors influencing students' attitudes to be psychiatrists. In order to counteract the lack of medical students becoming psychiatrists, it is important to provide more preclinical chances for students, and the country should also provide more positive guidance on psychiatry.

\section{DATA AVAILABILITY STATEMENT}

The raw data supporting the conclusions of this article will be made available by the authors, without undue reservation.

\section{ETHICS STATEMENT}

The studies involving human participants were reviewed and approved by the Ethics Committee of the Chongqing Medical University. The patients/participants provided their written informed consent to participate in this study.

\section{AUTHOR CONTRIBUTIONS}

$\mathrm{XL}$ conceived the structure of the manuscript and wrote the manuscript. XC collected the data. YG, JH, and YT analyzed the data. JZ, HY, MA, and LK critically reviewed the manuscript. All authors have read and approved the final manuscript.

\section{FUNDING}

This research was supported by the National Natural Science Foundation of China (No: 81971286), the Chongqing Higher Education Teaching Reform Research Project (Grant No.: 171012), Education and Teaching Research Project of Chongqing Medical University (Grant No.: JY170101), and the Chongqing Health Commission (Grant No.: 2020FYYX159; Grant No.: 2022MSXM058). The funding body had no involvement in study design, in the collection, analysis, and interpretation of data, in the writing of the report, and in the decision to submit the article for publication.

\section{ACKNOWLEDGMENTS}

The authors would like to thank the participating medical school for permission to conduct the study amongst students and the respondents for their participation.
4. National Health and Family Planning Commission of China. News Conference, April 7, 2017. Available online at: www.nhfpc.gov.cn

5. Phillips MR, Zhang JX, Shi QC, Song ZQ, Ding ZJ, Peng ST, et al. Prevalence, treatment, and associated disability of mental disorders in four provinces in China during 2001-05: an epidemiological survey. Lancet. (2009) 373:204153. doi: 10.1016/S0140-6736(09)60660-7

6. Feifel D, Moutier CY, Swerdlow NR. Attitudes toward psychiatry as a prospective career among students entering medical school. Am J Psychiatry. (1999) 156:1397-402.

7. Sierles FS, Taylor MA. Decline of US medical student career choice of psychiatry and what to do about it. Am 


\section{J Psychiatry. (1995) 152:1416-26. doi: 10.1176/ajp.152.10.} 1416

8. Dom G. Psychiatry, an attractive career choice? Tijdschr Psychiatr. (2011) 53:793-6.

9. Wiguna T, Yap KS, Tan BW, Siew T, Danaway J. Factors related to choosing psychiatry as a future medical career among medical students at the Faculty of Medicine of the University of Indonesia. East Asian Arch Psychiatry. (2012) 22:57-61.

10. Gowans MC, Wright BJ, Brenneis FR, Scott IM. Which students will choose a career in psychiatry? Can J Psychiatry. (2011) 56:605-13. doi: 10.1177/070674371105601006

11. Gowans MC, Glazier L, Wright BJ. Brenneis FR, Scott IM. Choosing a career in psychiatry: factors associated with a career interest in psychiatry among Canadian students on entry to medical school. Can J Psychiatry. (2009) 54:557-64. doi: 10.1177/070674370905400808

12. David MN, Lincoln K, Francisca OO, Mary K, Victoria M, Judy S, et al. Attitudes toward psychiatry: a survey of medical students at the University of Nairobi, Kenya. Acad Psychiatry. (2008) 32:1549. doi: 10.1176/appi.ap.32.2.154

13. Sierles FS, Dinwiddie SH, Patroi D, Atre-Vaidya N, Schrift MJ et al. Factors affecting medical student career choice of psychiatry from 1999 to 2001. Acad Psychiatry. (2003) 27:260-8. doi: 10.1176/appi.ap.27.4.260

14. Aghukwa NC. Attitudes towards psychiatry of undergraduate medical students at Bayero University, Nigeria. SAJP. (2010) 16:147-52. doi: 10.4102/sajpsychiatry.v16i4.239

15. Laugharne R, Appiah-Poku J, Laugharne J, Shankar R. Attitudes toward psychiatry among final-year medical students in Kumasi, Ghana. Acad Psychiatry. (2009) 33:71-5. doi: 10.1176/appi.ap.33.1.71

16. Curtis-Barton M, Eagles J. Factors that discourage medical students from pursuing a career in psychiatry. Psychiatrist. (2011) 35:425-9. doi: 10.1192/pb.bp. 110.032532

17. Lingeswaran A. Psychiatric curriculum and its impact on the attitude of Indian undergraduate medical students and interns. Indian J Psychol Med. (2010) 32:119-27. doi: 10.4103/0253-7176.78509

18. Ai M, Zhu D, Wu L, Zhang Q, Chen J, Chen X, et al. Investigation on the employment situations of graduates specialized in clinical medicine (mental hygiene specialty). Chin J Grad Med Educ. (2018) 4:301-5.

19. Burra P, Kalin R, Leichner P, Waldron JJ, Handforth JR, Jarrett FJ, et al. The ATP 30-a scale for measuring medical students' attitudes to psychiatry. Med Educ. (1982) 16:31-8. doi: 10.1111/j.1365-2923.1982.tb01216.x

20. Nielsen AC, Eaton JS. Medical students' attitudes about psychiatry: implications for psychiatric recruitment. Arch Gen Psychiatry. (1981) 38:1144-54. doi: 10.1001/archpsyc.1981.01780350078009

21. Balon R, Franchini GR, Freeman PS, Hassenfeld IN, Keshavan MS. Medical students' attitudes and views of psychiatry: 15 years later. Acad Psychiatry. (1999) 23:30-6. doi: 10.1007/BF03340033

22. Wang $X$, Xiang $X$, Hao $W$. An attitude toward psychiatry among medical students. J Cent South Univ. (2011) 36:903-7. doi: 10.3969/j.issn.1672-7347.2011.09.016

23. Abramowitz MZ, Bentov-Gofrit D. The attitudes of Israeli medical students toward residency in psychiatry. Acad Psychiatry. (2005) 29:925. doi: 10.1176/appi.ap.29.1.92

24. Farooq K, Lydall GJ, Malik A, Ndetei DM, ISOSCCIP Group, Bhugra D. Why medical students choose psychiatry - a 20 country cross-sectional survey. BMC Med Educ. (2014) 14:12. doi: 10.1186/1472-6920-14-12

25. Science and Technology Evaluation Metrics (STEM) of China's Hospitals, News Conference. Available online at: http://top100.imicams.ac.cn/subject?subject= 32057\&year $=2020$ (accessed October 31, 2021).

26. Borg N, Testa L, Sammut F, Cassar D. Attitudes of medical students in Malta toward psychiatry and mental illness. Acad Psychiatry. (2020) 44:70913. doi: 10.1007/s40596-020-01304-y

27. Budd S, Kelley R, Day R, Vard Hien, Dogra N. Student attitudes to psychiatry and their clinical placements. Med Teach. (2011) 33:e58692. doi: 10.3109/0142159X.2011.610836

28. Hor ESL, Russel V, Vasudevan U, O' Brien F. Changing attitudes to psychiatry and interest in the specialty as a career choice during clinical undergraduate years at a medical school in Penang, Malaysia. Ir J Med Sci. (2020) 189:2539. doi: 10.1007/s11845-019-02064-x

29. Aslam M, Taj T, Ali A, Badar N, Saeed F, Abbas M, et al. Psychiatry as a career: a survey of factors affecting students' interest in psychiatry as a career. McGill J Med. (2009) 12:7-12. doi: 10.26443/mjm.v12i1.730

30. Harris MG, Gavel PH, Young JR. Factors influencing the choice of specialty of Australian medical graduates. Med J Aust. (2005) 183:295300. doi: 10.5694/j.1326-5377.2005.tb07058.x

31. Maric NP, Stojiljkovic D, Milekic B, Milanov M, Bijelic J. Change of students' interest in psychiatry over the years at School of Medicine, University of Belgrade, Serbia. Isr J Psychiatry Relat Sci. (2011) 48:42-8.

32. El-Gilinya A, Hamdeyb I, Fawzyc M, Elwasify M, Elwasify M, Barakat D. Attitude toward psychiatry among interns in Egypt. Middle East Current Psychiatry. (2018) 25:29-33. doi: 10.1097/01.XME.0000526693.27 432.40

33. Zwerenz R, Barthel Y, Leuzinger-Bohleber M, Gieler U, Rudolf G, Schwarz R, et al. Attitudes of medical students towards psychotherapeutic treatment and training. Z Psychosom Med Psychother. (2007) 53:25872. doi: $10.13109 / \mathrm{zptm} .2007 .53 .3 .258$

34. Kuhnigk O, Hofmann M, Böthern AM, Haufs C, Bullinger M, Harendza $S$. Influence of educational programs on attitudes of medical students towards psychiatry: effects of psychiatric experience, gender, and personality dimensions. Med Teach. (2009) 31:e303-10. doi: 10.1080/014215908026 38048

35. Baller FA, Ludwig KV, Kinas-Gnadt Olivares CL, Graef-Calliess IT. Exploring the ideas and expectations of German medical students towards career choices and the speciality of psychiatry. Int Rev Psychiatry. (2013) 25:42530. doi: 10.3109/09540261.2013.823384

36. Andermann LF, De Souza C, Lofchy J. The Psychiatry Institute for Medical Students: a decade of success. Acad Psychiatry. (2010) 34:1503. doi: 10.1176/appi.ap.34.2.150

37. Alexander DA, Eagles JM. Attitudes of men and women medical students to psychiatry. Med Educ. (1986) 20:44955. doi: 10.1111/j.1365-2923.1986.tb01192.x

38. Fabrega H, Ulrich R, Keshavan M. Gender differences in how medical students learn to rate psychopathology. J Nerv Ment Dis. (1994) 182:4715. doi: 10.1097/00005053-199408000-00009

39. Cutler JL, Alspector SL, Harding KJ, Wright LL Graham MJ. Medical students' perceptions of psychiatry as a career choice. Acad Psychiatry. (2006) 30:1449. doi: 10.1176/appi.ap.30.2.144

40. Lee EK, Kaltreider N, Crouch J. Pilot study of current factors influencing the choice of psychiatry as a specialty. Am J Psychiatry. (1995) 152:10669. doi: 10.1176/ajp.152.7.1066

41. Li X, Ai M, Zhang K, Kuang L, Chen J. The exploration and practice of "five stage integration" full tutorial system for the standardized residency training of psychiatric medicine. Chin J Grad Med Educ. (2019) $1: 62-4$.

Conflict of Interest: The authors declare that the research was conducted in the absence of any commercial or financial relationships that could be construed as a potential conflict of interest.

Publisher's Note: All claims expressed in this article are solely those of the authors and do not necessarily represent those of their affiliated organizations, or those of the publisher, the editors and the reviewers. Any product that may be evaluated in this article, or claim that may be made by its manufacturer, is not guaranteed or endorsed by the publisher.

Copyright (c) 2022 Li, Ai, Chen, Gan, He, Tian, Zhai, Yang and Kuang. This is an open-access article distributed under the terms of the Creative Commons Attribution License (CC BY). The use, distribution or reproduction in other forums is permitted, provided the original author(s) and the copyright owner(s) are credited and that the original publication in this journal is cited, in accordance with accepted academic practice. No use, distribution or reproduction is permitted which does not comply with these terms. 